\title{
Percepção de Genitoras sobre a Intervenção Neuropsicomotora em Crianças com Microcefalia
}

\author{
Perception of Mothers about the Neuropsychomotor \\ Intervention in Children with Microcephaly
}

\section{Percepción de Madres en la Intervención Neuropsicomotora en Niños con Microcefalia}

\author{
Thiciane Felix Portela ${ }^{1}$, Lícia Maria Belchior Almeida², Luciana Dias \\ Belchior $^{3}$
}

1.Fisioterapeuta, Graduada em Fisioterapia pela Universidade de Fortaleza, Centro de Ciências da Saúde, Fortaleza-CE, Brasil. ORCID: https://orcid.org/0000-0002-8939-0425

2.Graduanda em Medicina pela Universidade Federal do Ceará, Faculdade de Medicina, Fortaleza-CE, Brasil. ORCID: https://orcid.org/0000-0002-9939-1085

3.Fisioterapeuta, Doutora em Farmacologia pela Universidade Federal do Ceará, Faculdade de Medicina, Fortaleza-CE, Brasil. ORCID: https://orcid.org/0000-0001-5270-6417

\begin{abstract}
Resumo
Introdução. A microcefalia é uma malformação congênita, em que a medida do perímetro cefálico ao nascimento encontra-se menor que a definida pela OMS. Objetivo. Descrever a percepção de genitoras acerca da intervenção neuropsicomotora em crianças com microcefalia. Método. Estudo qualitativo, caráter descritivo, com mães de crianças com diagnóstico clínico de microcefalia atendidas de março a abril de 2017. Foi realizada uma entrevista com as mães, seguindo um roteiro semiestruturado. A pesquisa obedeceu à resolução $466 / 12$ do Conselho Nacional de Saúde e teve início após aprovação do Comitê de Ética e Pesquisa da UNIFOR. Resultados. Foi possível evidenciar a dificuldade de debate acerca da doença, que se deve, em parte, à frustração das mães quanto às perspectivas que idealizam para os filhos, como frequentar a escola, condição limitada pela microcefalia. Ainda mais quando as mães não têm conhecimento da doença e das possibilidades terapêuticas deste processo. A intervenção neuropsicomotora, em contrapartida, vem a ser uma das possibilidades terapêuticas com mais relevância, devido ao potencial de melhora da qualidade de vida. Conclusão. A intervenção neuropsicomotora estimula, precocemente, traços cognitivos, motores e sensitivos, para trazer qualidade de vida para a criança e suporte para a família.
\end{abstract}

Unitermos. Percepção; Microcefalia; Intervenção Precoce

\begin{abstract}
Introduction. Microcephaly is a congenital malformation, in which the head circumference at birth is smaller than that defined by the WHO. Objective. To describe the perception of mothers about neuropsychomotor intervention in children with microcephaly. Method. Qualitative, descriptive study, with mothers of children with a clinical diagnosis of microcephaly seen from March to April 2017. An interview was conducted with the mothers, following a semistructured script. The research complied with resolution 466/12 of the National Health Council and started after approval by the Ethics and Research Committee of UNIFOR. Results. It was possible to evidence the difficulty of debate about the disease, which is due, in part, to the mothers' frustration regarding the perspectives they idealize for their children, such as attending school, a condition limited by microcephaly. Especially when mothers are unaware of the disease and the therapeutic possibilities of this process. Neuropsychomotor intervention, on the other hand, is one of the most relevant therapeutic possibilities, due to the potential for improving quality of life. Conclusion. The neuropsychomotor intervention stimulates, precociously, cognitive, motor, and sensory traits, to bring quality of life for the child and support for the family.
\end{abstract}

Keywords. Perception; Microcephaly; Early Intervention 


\section{Resumen}

Introducción. La microcefalia es una malformación congénita, en la cual la circunferencia de la cabeza al nacer es más pequeña que la definida por la OMS. OBJETIVOS: Describir la percepción de las madres sobre la intervención neuropsicomotora en niños con microcefalia. Método. Estudio cualitativo, descriptivo, con madres de niños con diagnóstico clínico de microcefalia visto de marzo a abril de 2017. Se realizó una entrevista con las madres, siguiendo un guión semiestructurado. La investigación cumplió con la resolución 466/12 del Consejo Nacional de Salud y comenzó después de la aprobación del Comité de Ética e Investigación de UNIFOR. Resultados. Fue posible evidenciar la dificultad del debate sobre la enfermedad, que se debe, en parte, a la frustración de las madres con respecto a las perspectivas que idealizan para sus hijos, como asistir a la escuela, una condición limitada por la microcefalia. Especialmente cuando las madres desconocen la enfermedad y las posibilidades terapéuticas de este proceso. La intervención neuropsicomotora, por otro lado, es una de las posibilidades terapéuticas más relevantes, debido al potencial para mejorar la calidad de vida. Conclusiones. La intervención neuropsicomotora estimula, precozmente, los rasgos cognitivos, motores y sensoriales, para brindar calidad de vida al niño y apoyo a la familia.

Palabras clave. Percepción; Microcefalia; Intervención Precoz

Trabalho realizado na Universidade de Fortaleza, Fortaleza-CE, Brasil.

\section{INTRODUÇÃO}

No Brasil, a incidência de microcefalia parece ter aumentado pelo Zika vírus, o qual é transmitido pelo mosquito Aedes Aegypti. Desde outubro de 2015 até julho de 2017, foram notificados 13.835 casos de microcefalia referentes a esse vírus, e, confirmados foram 2.753 casos. De acordo com o Ministério da Saúde, as demandas estão sendo monitorados e tendo assistência tanto para as mães como para os filhos ${ }^{1,2}$. No Nordeste brasileiro, a preocupação das ocorrências de crianças com microcefalia é ainda mais alarmante, seja pelo fato de que $90 \%$ das notificações em todo o Brasil são nesta região, seja pela falta de especialistas que corroborem o auxílio de tais famílias ${ }^{3-5}$. 
A microcefalia é uma malformação congênita, em que a medida do perímetro cefálico ao nascimento encontra-se menor que a média definida pela Organização Mundial da Saúde (OMS), que é menor ou igual a $33 \mathrm{~cm}$ de comprimento, causando distúrbios neurológicos que podem acometer 0 desenvolvimento sensório motor, sendo diagnosticada no início da gestação ou ao nascimento, já que o cérebro não crescerá o suficiente, comprometendo, assim, o sistema nervoso central ${ }^{6,7}$.

Com etiologia complexa e multifatorial, tal afecção pode envolver fatores genéticos e ambientais. Dentre os diversos problemas que essa anormalidade pode acometer na criança, destacam-se epilepsia, paralisia cerebral, retardo do desenvolvimento cognitivo, motor e da fala, além de problemas de visão e audição ${ }^{8}$. Outras consequências são atraso mental, paralisia, distonia muscular com dependência de longo prazo para cuidados básicos como andar, comer e falar.

A intensa descoberta de casos de microcefalia, inicialmente, no Nordeste brasileiro gerou intensa comoção em pouco tempo. Esse panorama refletiu a importância de uma maior atenção aos eventos ligados à saúde da mulher $\mathrm{e}$ ao desenvolvimento neuropsicomotor dos bebês. Além disso, a grande cobertura midiática refletia o pânico do crescimento dessa epidemia em um cenário de intensa interconectividade ${ }^{9}$.

É essencial cuidado e atenção, os quais irão requisitar dedicação exclusiva de algum membro familiar, geralmente 
das mães. A genitora tem um papel importante na rotina de seus filhos, especialmente naqueles com alguma patologia, contribuindo para um tratamento eficaz no qual a mãe passa segurança e confiança para esses filhos, interferindo positivamente na qualidade de vida. Assim sendo, há necessidade do conhecimento materno na área do desenvolvimento e das manifestações dessa patologia a fim de facilitar o cuidado ${ }^{10}$.

O tratamento da microcefalia é baseado na estimulação neuropsicomotora das crianças, e ações de suporte ao desenvolvimento devem ser estabelecidas com brevidade. 0 Ministério da Saúde desenvolveu um protocolo específico para o acompanhamento desses pacientes. $O$ conceito Bobath é um recurso que ajuda na estimulação dos movimentos funcionais o mais próximo possível da normalidade ${ }^{11,12}$. Além desse, a Integração Sensorial favorece e desencadeia estímulos diferenciados para o tato, o olfato, a audição, a visão e o paladar, contribuindo para que 0 acometido diferencie os tipos de sensibilidade ${ }^{13,14}$.

Assim, o protocolo terapêutico inserido em uma equipe multiprofissional tem papel decisivo no favorecimento de um desenvolvimento neurofuncional mais adequado para cada caso. A estimulação neuropsicomotora, sensorial, cognitiva e do aparelho respiratório aliada ao correto acompanhamento multiprofissional influenciará na qualidade de vida do paciente e de toda a sua família ${ }^{15}$.

O objetivo do presente estudo foi analisar a percepção das genitoras sobre a saúde das crianças com microcefalia e 
os efeitos da intervenção neuropsicomotora precoce no Núcleo de Atenção Médica Integrada.

\section{MÉTODO}

\section{Amostra}

Tratou-se de um estudo qualitativo, de caráter descritivo, realizado no Núcleo de Atenção Médica Integrada (NAMI), em Fortaleza, Ceará, no período de março a abril de 2017, constituído por mães de pacientes com Microcefalia, atendidas no período de 2016-2017, totalizando uma amostra de 03 genitoras. Inicialmente, havia 5 participantes que atendiam ao perfil do estudo. Contudo uma das mães negou-se em participar e outra foi transferida do atendimento prestado no referido serviço, restando 3 mães, as quais foram selecionadas.

Este trabalho seguiu as normas da resolução 466/12 do Conselho Nacional de Saúde que trata das pesquisas com seres humanos, sendo aprovado pelo Comitê de Ética da Universidade de Fortaleza (UNIFOR) com Número do Parecer: 1.835 .089 .

\section{Procedimento}

O estudo iniciou-se mediante contato inicial com 0 Diretor do Núcleo de Atenção Médica Integrada, solicitandose autorização para realizar-se entrevista com roteiro semestruturado. Para o recrutamento da amostra, foram espalhados cartazes no NAMI, próximos aos locais de 
atendimento do público alvo, com explicações sobre a pesquisa, marcando-se um encontro inicial que teve como tema: "O Papel da Intervenção Neuropsicomotora na Microcefalia". Nesse momento, as participantes foram esclarecidas sobre os objetivos do estudo, bem como de seus direitos a serem resguardados pelo Termo de Consentimento Livre e Esclarecido (TCLE), consistindo a assinatura desse como condição essencial para participação. Marcou-se o primeiro encontro do grupo focal para esclarecer sobre a metodologia proposta, sendo posteriormente utilizada como técnica de coleta entrevistas individuais com questões estruturadas e semiestruturadas sobre o tema. As perguntas foram divididas em quatro bloco temáticos. O roteiro semiestruturado contemplou os seguintes aspectos: 1. "Dados pessoais e sociodemográficos"; 2. "Microcefalia"; 3. "Atividades rotineiras"; 4. "Intervenção neuropsicomotora".

As entrevistas foram realizadas em ambiente calmo e seguro, onde a mãe pôde expor todas as suas percepções, gravadas por um aparelho Lenovo de modelo Vibe K5 de cor dourado e posteriormente transcritas, compondo o banco de informações da pesquisa.

\section{Análise dos Dados}

A análise dos dados foi feita a partir da Análise de Conteúdo de Bardin (2011) ${ }^{16}$. Essa revelou que "o método qualitativo é o que se aplica ao estudo da história, das representações, das crenças, das percepções e das opiniões, produtos das interpretações que os humanos fazem a 
respeito de como vivem, constroem seus artefatos e a si mesmos, sentem e pensam". Desta forma, elencaram-se categorias a partir das respostas dadas pelas genitoras.

\section{RESULTADOS}

A amostra constou de três mães, com idade média de 22,6 anos, sendo a mais nova com faixa etária de 18 anos e a mais velha com 27 anos de idade. Quanto ao trabalho, uma mãe tem categoria profissional e duas das mães não têm trabalho formal, tendo como atividade somente o cuidado da casa e dos filhos.

Dois dos companheiros trabalham como seguranças e um como pedreiro, com renda familiar média de 1.516,66 reais. Quanto à religião, duas das genitoras são católicas e uma evangélica. A média de filhos por família foi de 1,6.

Elencaram-se as principais categorias dos discursos advindos das entrevistas visando à melhor compreensão quanto às discussões a serem abordadas: 1. Microcefalia conceitos e percepções; 2. Rotina diária - A vida das mães; 3. Microcefalia e Intervenção neuropsicomotora - Percepção das mães quanto ao papel da estimulação precoce.

\section{Microcefalia - conceitos e percepções}

Ao serem questionadas sobre a primeira vez que ouviram falar sobre microcefalia, duas mães ( $M 1, M 2$ ) relataram ter tido conhecimento durante o surto relacionado 
ao Zika vírus, em 2016, com as campanhas de divulgação apresentadas pelos veículos de comunicação em massa (televisão, rádio, internet). A outra genitora (M3) relata ter tido conhecimento acerca da temática somente depois do nascimento do filho.

"A primeira vez que eu ouvi falar de microcefalia era quando eu estava grávida, no tempo dos mosquitos. Foi em 2016..." M1

"Bem antes de ter meu filho, estavam divulgando bem muito na televisão. Aí surgiu já antes de saber alguma coisa. Eu soube quando estava com 2 meses de gestação." M2

Ressalta-se ainda a inapropriada forma como a notícia fora dada a uma das mães (M3), já que esta relata que a fala do profissional fora terrível, além de não fornecer explicações quando a mãe o questionara, deixando dúvidas.

\footnotetext{
"Ouvi quando minha filha nasceu, que o médico disse de uma forma terrível... fiquei só com dúvidas na cabeça imaginando o que era e eu pedi pra ele me explicar e ele falou que após os exames ele me explicaria melhor." M3
}

Ao serem questionadas sobre o diagnóstico de seus filhos, uma das mães (M1) não admite a real doença microcefalia, e afirma que só se encontra em atendimento devido a uma convulsão, além de mostrar-se pouco 
receptiva ao tratar do assunto, demonstrando em várias partes da entrevista certo incômodo em falar sobre o quadro de saúde de seu filho.

Outra mãe (M2) relata o difícil momento do diagnóstico, não somente pela doença em si, mas também pela forma como a notícia foi transmitida pelo profissional. A última mãe (M3) já se mostrou mais resiliente ao demonstrar certa conformação com o estado de saúde da sua filha. Mesmo assim, ela também sentiu bastante ao receber o diagnóstico.

"É porque eles colocam uns nomes diferentes e eu não sei, mas pra mim ele passou 10 dias no antibiótico porque ele fez cocô na minha barriga e engoliu... O motivo exato foi devido à convulsão e não pela microcefalia." M1

"O médico não foi tão compreensivo com a gente. Ele deu a notícia como se "tanto faz", ele não foi sentindo com a gente. Foi doloroso, além de saber que meu filho ia ter problemas, não foi agradável a forma de falar. Pra gente foi horrível." M2

"Foi um "baque" para mim quando a médica falou, mas depois você vai aprendendo a conviver com aquela situação..." M3

Quanto à definição de microcefalia, nota-se que as mães (M1, M3) têm um entendimento limitado relativo à doença, com ênfase nas características físicas, como 
deformidades, "tamanho do cérebro menor", além das limitações impostas pela própria doença, a exemplo da menor expectativa de vida. Nota-se, também, certa resistência em definir as características da doença, ao passo que duas das mães (M2, M3) veem principalmente na intervenção neuropsicomotora uma possibilidade de seus filhos terem melhor qualidade de vida.

"...mas não tenho conhecimento sobre a doença. A gente vê uma criança deformada, pequenininha. A gente se coloca no lugar dos pais... Mas eu não conheço bem, não sei falar sobre." M1

"Eu tenho muita fé que meu filho vai andar como qualquer criança normal, sei que ele não vai ter uma desenvoltura normal como qualquer criança, eu não posso também querer que seja assim. Mas, eu creio, com a ajuda de vocês ele vai melhorar." M2

"Eu acho que a microcefalia é uma doença que ela pode ser superada, pouco a pouco, com o acompanhamento. O que dá pra saber se a criança tem microcefalia é que o cérebro da criança nasce menor..." M3

Nota-se que as mães confiam na intervenção neuropsicomotora para o desenvolvimento de seus filhos. Uma das mães (M1) chega a avaliar seu filho antes e depois 
da intervenção e comparar com outra filha que não tem a doença. Outra (M3) diz seguir também as orientações de estimulação da criança em casa, durante, por exemplo, o banho.

\begin{abstract}
"Ele desenvolveu muito viu, eu achava ele muito lento. Aonde eu colocava ... ele ficava. Você sabe como é criança de 3 meses. Tiro pela minha filha, eu comparo, acho ele lento pela coordenação motora..." M1
\end{abstract}

"Vejo que ela está indo muito bem. Tudo que a doutora está trabalhando aqui tento fazer em casa também, com isso ela segura as coisas com as mãos..." M3

Já outra mãe (M2) não notou mudança significativa no desenvolvimento de seu filho, ficando decepcionada com a situação da melhora das outras crianças e não de seu filho.

\footnotetext{
"Meu filho está vindo aqui há uns 10 meses, não vi ainda nenhuma melhora, pois me disseram que a evolução dele é bastante lenta, fico um pouco decepcionada com isso. Ver outras crianças evoluindo e ele não." M2
}

\title{
2. Rotina diária - A vida das mães
}

Nota-se que a rotina das mães (M1, M2, M3) é sobrecarregada, devido ao fato de elas se dividirem nas 
atividades de casa e do trabalho, além de se locomoverem para deixar seus filhos com parentes (avós, tias, irmãos e pais) e levá-los para os atendimentos de saúde. Ressalta-se o papel das avós que participam ativamente da rotina dessas crianças, financeira e emocionalmente.

\begin{abstract}
"Quando ele acorda de manhã, pronto ali é só pra eu brincar com ele. Toda terça e quinta tenho a rotina de vir com ele para cá, né! Em casa, deixo um brinquedo no chão e ele brinca, quando é perto do meio dia eu já dou o alimento dele, no caso o caldo de feijão é a comida preferida dele..." M1
\end{abstract}

"Passo a semana trabalhando, só tiro as manhãs para vir pra cá com ele, mas de manhã ele merenda e deixo com a avô, que é minha mãe, e falo para ela que tem que brincar com ele. Mas ele não entende muito não..." M2

"Durante o dia a gente faz alguns exercícios que a doutora ensina, como brincadeiras para estimular. Também compramos piscina inflável para ajudar ela a evoluir..." M3

Uma das mães (M2), entretanto, relatou que o pai não participa da vida diária do filho, recebendo unicamente a ajuda de sua mãe.

"Só recebo apoio só da minha mãe, quando tenho que trabalhar eu deixo na casa dela. 0 
pai nunca mais eu vi e nem quero saber dele."

A rotina das mães ( $M 1, M 2, M 3)$ mudou desde 0 nascimento de seus filhos. Duas mães (M1, M2) relatam como mudanças as consultas semanais e a assistência de saúde. Também se revela, no relato de uma dessas mães (M2), o preconceito da sociedade a partir da percepção de pena dentro do transporte público.

\begin{abstract}
"Totalmente diferente da minha primeira filha, tenho muito cuidado com ele de dar os remedinhos dele na hora, coisa que eu nunca liguei na primeira filha..." M1

"Olha, tiveram várias mudanças, como ir toda semana para o tratamento, pegar menos ônibus porque o pessoal sente pena e fica olhando mesmo..." M2
\end{abstract}

Uma mãe se locomove com carro próprio (M1), outra pelo transporte público (M2) e a última pelo transporte da prefeitura (M3).

"Venho no transporte da prefeitura do meu interior, basta eu pedir lá que eles me trazem." M3 
2.1 Dificuldades enfrentadas - acesso ao sistema de saúde

Duas mães (M1, M3) relataram dificuldades para acessar os serviços públicos de saúde. Uma delas (M1) elencou como principal dificuldade a longa lista de espera para conseguir os exames. A outra mãe (M3) relata que, por morar no interior, onde não encontra assistência qualificada, é necessário conseguir tal atendimento na capital.

\begin{abstract}
"O sistema não é muito bom não, você vai para o posto e não tem médico, não tem medicamento. Quando eu procurei o posto para o tratamento para meu filho, eles foram logo dizendo que não resolvia lá, que eu tinha que procurar outro canto..." M1
\end{abstract}

"Tive bastante dificuldade em conseguir algum atendimento de saúde para minha filha. Não sei se é porque eu sou do interior, por isso dificulta, mas tive que ralar pra conseguir uma assistência de saúde." M3

\title{
2.2 Dificuldades enfrentadas - Preconceito
}

É unânime o relato de preconceito vivenciado pelas mães na sociedade. Uma das mães (M1) é questionada quanto ao desenvolvimento motor de seu filho. Outra mãe (M2) vivencia no transporte público o preconceito pelo comportamento das pessoas. Por fim, a última genitora (M3) relata os questionamentos de outras mães na sala de espera da pediatra e também no distanciamento das pessoas. Essas 
formas de preconceito geram nas mães sentimento de culpa, sofrimento e medo.

"Olha, em casa eu não tenho, graças a Deus que não. Na sociedade, tenho porque algumas pessoas me questionam por que que meu filho ainda não anda, mas aquilo não me atinge, ele é querido por todo mundo, ele é simpático." M1

"A dificuldade maior é quando pego o ônibus, que as pessoas tratam o meu filho como um retardado..." M2

"Tive... tenho sim, muita dificuldade. Ir ao pediatra e na sala de espera, as pessoas ficarem me perguntando como foi que aconteceu com ela. Minha vontade, doutora, era sair correndo de lá chorando me sentindo culpada pelo problema da minha filha. E tem outras coisas, como ir ao supermercado e eu estava na fila preferencial, quando uma mulher grávida se distanciou de mim pensando que era contagioso." M3

\section{Microcefalia e Intervenção neuropsicomotora - Percepção das mães quanto ao papel da estimulação precoce}

Quanto aos atendimentos, a média de tempo foi de 12,3 meses. Orientações foram dadas às três mães, tais como, brincadeiras que estimulem o engatinhar, a fala, técnica de relaxamento como o banho morno e o rolinho. 
"Desde os 3 meses de idade, agora ele tem 1 ano e 1 mês." M1

"8 meses de tratamento. Passaram sim algumas orientações pra eu seguir, como não deixar de brincar, sempre falar com ele, pra ver se ele fala mais rápido." M2

"Faz 1 ano e 7 meses que minha filha faz os atendimentos. Falaram sim, como sempre estar me comunicando com ela. A brincadeira, que é muito importante pra ela se desenvolver. Colocar ela no rolinho, banho morno que ajuda a relaxar já que essas crianças são irritadas." M3

"Pra eu estimular ele em casa, brincando, colocar ele no chão pra engatinhar, colocar um brinquedo longe pra ver se ele vai pegar." M1

Nota-se, pela percepção de duas mães (M1, M3), o papel fundamental da intervenção neuropsicomotora, e como essa influencia no desenvolvimento das crianças, o que também contribui no modo como elas encaram o quadro de saúde dos seus filhos. Mediante a estimulação motora e cognitiva, a equipe multiprofissional auxilia na melhora da qualidade de vida. Entretanto, uma das genitoras (M2) não percebeu diferença a partir dos atendimentos. Além da intervenção neuropsicomotora, as mães relatam ser 
acompanhadas por outros setores: Fonoaudiologia, Terapia Ocupacional, Neurologia, Pediatria.

\begin{abstract}
"Quando coloca ele para engatinhar em casa ele tenta fazer. Outra coisa que eu tava reparando é que, quando ele tinha 8 meses, ele era mais quietinho e eu chamava muito atenção dele colocando o brinquedinho longe para ele pegar. Quando vai passando o tempo, a gente vai notando a diferença. Tem a fisioterapia, fonoaudióloga, terapia ocupacional, pediatra dele." M1
\end{abstract}

"Não vejo nada diferente com ele. Não sei se esse tratamento tá resolvendo o problema. Agora é só esperar. Além daqui ele é acompanhado pela terapia ocupacional, a fonoaudiologia para aprender a comer, o neurologista e a pediatra dele." M2

"Não sei ver minha filha sem o tratamento de vocês. Está sendo muito bom pra ela. Ela já quer pegar as coisas sozinha e, quando eu coloco a fralda nela, ela já quer tirar. Abre a mãozinha já. Recebo atendimento de uma equipe grande que tem a fisioterapia, a terapia ocupacional, a pediatra dela, o neurologista e a fonoaudiologia." M3 


\section{DISCUSSÃO}

Estudos relatam que a boa comunicação para a transmissão de diagnósticos difíceis depende de fatores como: Ouvir/Conhecer o paciente; Esclarecer todas as suas dúvidas; Criar espaços/momentos nos quais se possa expressar suas emoções; Criar e organizar estratégias relacionadas a tranquilizar/emponderar o paciente ou seu familiar de conhecimento ${ }^{16-18}$, o que não foi evidenciado, algumas vezes, na relação profissional-paciente no presente estudo.

O desenvolvimento das crianças depende da interação indivíduo, ambiente e tarefa ${ }^{19}$. A intervenção neuropsicomotora é um exemplo de como atividades podem ajudar no desenvolvimento da criança. No entanto, somente o tratamento não dá a certeza de uma melhora no quadro de saúde, mas sim um potencial de melhor qualidade de vida.

Situações inesperadas, como o nascimento de um filho com determinada patologia, podem gerar instabilidade familiar, principalmente quando a família já não possui uma estrutura mínima de suporte para sua organização ${ }^{20}$, corroborando a fala de uma das mães, uma vez que a participação do pai pode influenciar na organização da rotina de vida da família.

Qualquer dissemelhança a padrões pré-estabelecidos pode ser entendido como preconceito ${ }^{21}$, o que pode ser evidenciado pelo relato das mães. Tal circunstância pode vir, em parte, de uma sociedade que enaltece o normal, o perfeito, a estética, a função social e do desconhecimento. 
A Instrução Operacional MDS/MS N01, que trata dos procedimentos e rotinas conjuntas de atenção às famílias no âmbito do Sistema Único de Assistência Social; a Portaria Interministerial N 405, que institui, no âmbito do Sistema Único de Saúde e do Sistema Único de Assistência Social, a estratégia de ação rápida para o fortalecimento da atenção à saúde e da proteção social de crianças com microcefalia; o Instrumento Operacional MDS/MS N02, que implementa a Estratégia de Ação Rápida para o Fortalecimento da Atenção à Saúde e da Proteção Social das Crianças com Microcefalia; e a Lei N 13.301, que dispõe sobre a adoção de medidas de vigilância em saúde relacionadas a doenças como dengue, zika e chikungunya são ordenamentos do Ministério da Saúde, os quais visam ao cuidado de pacientes com microcefalia e suas famílias ${ }^{12}$.Tal panorama comprova a relevância da intervenção do Estado com o escopo de oferecer à população uma assistência completa à saúde.

O papel da equipe multiprofissional é necessário para que a criança com microcefalia possa se desenvolver com o maior potencial de possibilidades. A intervenção neuropsicomotora realizada pela equipe ajuda a estimular traços cognitivos, motores e sensitivos, a fim de trazer não somente qualidade de vida para a criança, mas também confiança e suporte para a família. 


\section{CONCLUSÃO}

Conclui-se que as genitoras abordadas na entrevista semiestruturada, que trata de temas como microcefalia, rotina diária e intervenção neuropsicomotora, destacaram como importante o papel da equipe multiprofissional no cuidado aos seus filhos, bem como a disponibilidade dos serviços de saúde oferecidos pelo Estado. Nessa mesma perspectiva, a função da família auxilia no desenvolvimento das capacidades funcionais dos pacientes. No entanto, alguns posicionamentos foram destacados quanto ao desconhecimento social acerca da patologia, o que caracteriza o preconceito. Evidencia-se, ainda, a melhora na qualidade de vida das crianças tratadas, segundo o relato das mães. Como limite desta pesquisa, ressalta-se o número de participantes, diante de restrições circunstanciais.

\section{REFERÊNCIAS}

1. Ministério da Saúde do Brasil. Microcefalia: Ministério da Saúde confirma 2.753 casos no país. (endereço na Internet). (atualizado em 2017; citado em 2020). Disponível em: http://www.cff.org.br/noticia.php?id =4533\&titulo=Brasil+confirmou+ 322+casos+de+beb\%C3\%AAs+com+microcefalia+e+outras+altera $\% \mathrm{C} 3 \% \mathrm{~A} 7 \% \mathrm{C} 3 \% \mathrm{~B} 5$ es+ligadas+\%C3\%A0+zika+em+2017

2.Gomes FC, Lopes JO, Fonsêca SMC. A importância da integração sensorial em crianças portadoras de transtornos de processamento sensorial - uma visão fisioterapeutica. (Endereço na Internet). Salvador (atualizado em 2014; citada em 2020). Disponível em: http://bibliotecaatualiza.com.br/arquivotcc/FPN/FPN09/GOMESfernanda-LOPES-juliana-FONSECA-shirlei.pdf

3.Cabral CM, Nóbrega MEB, Leite PL, Souza MSF, Teixeira DCP, Cavalcante TF, et al. Descrição clínico-epidemiológica dos nascidos vivos com microcefalia no estado de Sergipe, 2015. Epidemiol Serv Saúde 2017;26:245-54.

https://doi.org/10.5123/s167949742017000200002 
4. Marinho F, Araújo VEM, Porto DL, Ferreira $\mathrm{HL}$, Coelho MRS, Lecca RCR, et al. Microcefalia no Brasil: prevalência e caracterização dos casos a partir do Sistema de Informações sobre Nascidos Vivos (Sinasc), 2000-2015. Epidemiol Serv Saúde 2016;25:701-12. https://doi.org/10.5123/s1679-49742016000400004

5.Vargas A, Saad E, Dimech GS, Santos RH, Sivini MAVC, Albuquerque LC, et al. Características dos primeiros casos de microcefalia possivelmente relacionados ao vírus Zika notificados na Região Metropolitana de Recife, Pernambuco. Epidemiol Serv Saúde 2016; 25:691-700. http://dx.doi.org/10.5123/S1679-49742016000400003

6.Souza WV, Araújo TVB, Albuquerque MFPM, Braga MC, Ximenes RAA, Miranda-Filho DB, et al. Microcefalia no Estado de Pernambuco, Brasil: características epidemiológicas e avaliação da acurácia diagnóstica dos pontos de corte adotados para notificação de caso. Cad Saúde Pública 2016;32:e00017216. https://doi.org/10.1590/0102-311X00017216

7. Willrich A, Azevedo CCF, Fernandes JO. Desenvolvimento motor na infância: influência dos fatores de risco e programas de intervenção. Rev Neurocienc 2009; 17:51-6.

https://doi.org/10.34024/rnc.2009.v17.8604

8. Nunes ML, Carlini CR, Kalil-Neto D, Marinowic F, Fiori HH, Scotta MC, et al. Microcephaly and Zika virus: a clinical and epidemiological analysis of the current outbreak in Brazil. J Pediatr (RJ) 2016;92:23040. https://doi.org/10.1016/j.jped.2016.02.009

9.Souza WV, Melo-Filho DA, Valongueiro S, Melo APL, Brandão-Filho SP, Martelli CMT, et al. Epidemia de microcefalia e vírus Zika: a construção do conhecimento em epidemiologia. Cad Saúde Pública 2018;34:1-14. https://doi.org/10.1590/0102-311x00069018

10.Ministério da Saúde. Secretaria de Vigilância em Saúde. Departamento de Vigilância das Doenças Transmissíveis. Protocolo de vigilância e resposta à ocorrência de microcefalia e/ou alterações do sistema nervoso central (SNC) / Ministério da Saúde, Secretaria de Vigilância em Saúde, Departamento de Vigilância das Doenças Transmissíveis. Brasília: Ministério da Saúde, 2a edição, 2016, 55p. https://pesquisa.bvsalud.org/portal/resource/pt/lil-786728

11. Machado W. Microcefalia, deficiência, reabilitação, dependência e cuidador domiciliar: Preocupações com efeitos tardios da epidemia Zika vírus. Rede Humaniza SUS (endereço na Internet). Rio de Janeiro (atualizado em: 2016; citado em: 2020. Disponível em: http://redehumanizasus.net/93859-microcefalia-deficienciareabilitacao-dependencia-e-cuidador-domiciliar-preocupacoes-comefeitos-tardios-da-epidemia-zika/

12.Ministério da Saúde. Ministério do Desenvolvimento Social. Assistência Social no atendimento à microcefalia (endereço na Internet). (Atualizado em: 2017; citado em 2020). Disponível em: http://mds.gov.br/assuntos/assistencia-social/assistencia-social-noatendimento-a-microcefalia

13.Castilho-Weinert LV, Forti-Bellani CD. Abordagem Fisioterapêutica pelo Conceito Neuroevolutivo Bobath. In: Castilho-Weinert LV, Forti- 
Bellani CD (eds). Fisioterapia em Neuropediatria. São Paulo: OmniPax Editora, 2011, Cap.3, p.43-86.

http://omnipax.com.br/livros/2011/FNP/FNP-cap3.pdf

14.Beltrame B. Entenda o que é microcefalia (endereço na Internet. Portugal. (atualizado em: 2016; citado em: 2020). Dsiponível em: http://gerardocristino.com.br/novo/index.php/component/k2/item/15 4-entenda-o-que-\%C3\%A9-microcefalia

15. Cambricoli F, Frazão H, Bernardes M. Mães sofrem sem especialistas para bebês (endereço na Internet). Jornal o Estadão de São Paulo. (atualizado em: 2016; citado em: 2020). Disponível em: https://tudosobre.estadao.com.br/ministerio-da-SAUDE

16.Bardin L. Análise de conteúdo. São Paulo: Edição 70, 2011, 229p. http://www.reveduc.ufscar.br/index.php/reveduc/article/view/291/15 $\underline{6}$

17.Carrapa ASGCN. Comunicar Más Notícias em Pediatria. Rev Facul Med Lisboa 2010.2 https://repositorioaberto.up.pt/bitstream/10216/50120/2/Comunicar\%20Ms\%20Notcias $\% 20$ em\%20Pediatria.pdf

18.Souza ASR, Souza AI, Faquin SLL, Santos-Neto OG, Honorato E, Mattos $A G L$, et al. Altered intrauterine ultrasound, fetal head circumference growth and neonatal outcomes among suspected cases of congenital Zika syndrome in Brazil. Rev Bras Saude Mater Infant 2016;16(Suppl 1):S7-15. $\quad$ https://doi.org/10.1590/18069304201600 s100002

19.Parecer sobre estimulação precoce e microcefalia. Associação Brasileira de Fisioterapia Neurofuncional (endereço de internet). Rio de Janeiro (atualizado em: 2016; citado em: 2020). Disponível em: https://abrafin.org.br/wp-content/uploads/2015/02/PARECERMICROCEFALIA.pdf

20.Felix VPSR, Farias AM. Microcefalia e dinâmica familiar: a percepção do pai frente à deficiência do filho. Cad Saúde Pública 2019;34:1-11. https://doi.org/10.1590/0102-311x00220316

21.Traiber C, Lago PM. Comunicação de más notícias em pediatria. Bol Cient Ped 2012;1:3-7.

https://www.sprs.com.br/sprs2013/bancoimg/131210152030bcped 12 01 02.pdf 